\title{
Propagation techniques of Prinsepia utilis Royle
}

\author{
Vivek pandey ${ }^{1}$, Parvez daudi ${ }^{2}$ \\ Research wing of Uttarakhand, Forest Department, Nainital, India
}

\begin{abstract}
Pinsepia utilis is a medicinal shrub species which produces very useful edible oil from seed. Recently population of this valuable species is declining rapidly due to anthropogenic and modernization activities in its habitat. The objective of the present study was to develop nursery techniques of Prinsepia utilis through seed and cutting. Therefore an experiment was carried out by seed sowing in different medium (sand, sand + soil, vermiculite) \& different places (mist chamber, shade net, open beds) with different pre-sowing water treatments ( normal water soaking for 12 hours, warm water soaking for 12 hours and control). The result indicated that highest seed germination $(95 \%)$ was observed after warm water soaking for 12 hours with soil in mist chamber followed by treatment of warm water soaking for 12 hours $92 \%$ with sand + soil (1:1) in mist chamber. Vegetative propagation was conducted with half ripe shoot cuttings prepared from healthy and vigorous plants. Cuttings were treated with different IBA (Indole 3 butyric acid) concentration and Rootex powder. Pre-treated cuttings were planted in sand under mist chamber and shade house. The cuttings were pre-treated with Rootex-3 performed the best (38\% rooting) in mist chamber. IBA $5000 \mathrm{ppm}$ and IBA $3000 \mathrm{ppm}$ reduced the rooting percentage as $23 \%$ and $20 \%$ respectively.
\end{abstract}

Keywords: Seed sowing, vegetative propagation, IBA, natural regeneration

\section{INTRODUCTION}

Prinsepia utilis is perennial deciduous shrub belongs to family Rosaceae. It is locally known as Bhekal or Jhatalu in Uttarakhand. It is found from $3000 \mathrm{ft}$ to $9500 \mathrm{ft}$ in secondary scrub and commonly in sunny places. The flowering period varies from December to April and fruit ripen in the month of May-July. (A.E. Osmaston, 1926) The seed yield about 35 to $40 \%$ fatty and edible oil. The oil has rufefacient properties, applied externally in the treatment of rheumatism and muscular pain resulting from fatigue (N.S. Chauhan 1999). The seed oil is used in cooking and externally used in the treatment of coughs and colds. The seedcake paste applied in the treatment of ringworm or eczema and hot oilcake give relieve in stomach aches. (N. P. Manandhar, 2002) It grows better in sunny and open places (A. Huxley, 1992) which can be used for hedge and margin land plantation. Its root, stem and leaf were used by indigenous people for curing skin ailments and diseases (Pu, Z.H., et al., 2014). So it appears to be highly important to develop its propagation techniques and generate awareness amongst the masses along with its regular conservation in wild.

\section{MATERIAL AND METHODOLOGY}

\section{DESCRIPTION OF EXPERIMENTAL AREA}

The experiment was conducted in the Sadiatal nursery of Research wing of Uttarakhand forest department at Nainital from 2010 to 2013 . The area is situated at N $29^{0}$ $22.751^{\prime}$ latitude and $\mathrm{E} 79^{\circ} 25.955^{\prime}$ longitude at an altitude of $1775 \mathrm{~m}$. The climate of the area is temperate. Temperature ranging from $1^{0} \mathrm{C}$ to $30^{\circ} \mathrm{C}$ and receive 1800 $\mathrm{mm}$ annual rainfall. Frost occurs December to February and snowfall occasionally occurs in winter.

\section{III.EXPERIMENTAL MATERIAL AND DESIGN}

The cuttings of half ripe shoots of Prinsepia utilis were collected from healthy and vigorous plants. $15 \mathrm{~cm}$ long cuttings were prepared and immediately treated with IBA (Indole 3 Butyric Acid) 4000 PPM (400mg/100g),
IBA 5000 PPM $(500 \mathrm{mg} / 100 \mathrm{~g})$ and IBA $6000 \mathrm{ppm}$ $(600 \mathrm{mg} / 100 \mathrm{~g})$. IBA concentration was prepared in Chalk powder. Both treated and untreated cuttings were tagged and planted in mist-chamber in sand beds at $5 \mathrm{~cm}$ spacing. Humidity was maintained above $60 \%$, temperature $25^{\circ} \mathrm{c}$ to $35^{\circ} \mathrm{c}$ and fogging one minute at 30 minutes interval. Experiment consisted of 4 treatments and each treatment was replicated thrice with 30 cuttings per treatment. Three years data were analyzed and best results shown in table 1 .

The seeds of Prinsepia utilis were collected from Nainital region of Uttarakhand during late April-May. Pulp was removed immediately after seed collection and dried in shady place. The seed weight of 30 seeds was found to be $5 \mathrm{gm}$. Germination studies were conducted in mist chamber, shade house and open beds. The different medium sand, sand+soil (1:1) and soil were used for seed germination. The seeds were presoaked in normal water for 12 hours and warm water for 12 hours with control treatment. 20 seed were taken for per treatment per medium per replication. Data were analyzed and best results shown in table 2 .

TABLE 1: ROOTING AND SPROUTING PERCENTAGE IN DIFFERENT IBA PPM.

\begin{tabular}{|c|c|c|}
\hline Treatment & Sprouting (\%) & Rooting (\%) \\
\hline MT1P1 & 12 & 6 \\
\hline MT2P1 & 22 & 20 \\
\hline MT3P1 & 23 & 23 \\
\hline MT4P1 & 51 & 38 \\
\hline MT1P2 & 7 & 3 \\
\hline MT2P2 & 13 & 9 \\
\hline MT3P2 & 10 & 7 \\
\hline MT4P2 & 9 & 7 \\
\hline
\end{tabular}

$\mathrm{M}=$ sand, $\mathrm{T} 1=\mathrm{IBA} 1000 \mathrm{ppm}, \mathrm{T} 2=\mathrm{IBA} 3000 \mathrm{ppm}, \mathrm{T} 3=$ IBA $5000 \mathrm{ppm}, \mathrm{T} 4=$ Rootex, $\mathrm{C}=$ control, $\mathrm{P} 1=$ mist chamber, $\mathrm{P} 2=$ mist chamber 
International Advanced Research Journal in Science, Engineering and Technology

Vol. 2, Issue 10, October 2015

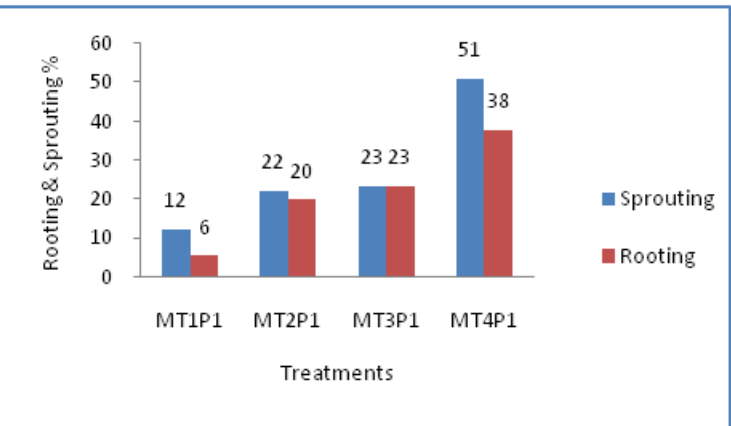

Fig. 1. Effect of IBA concentration on sprouting \& rooting percentage in mist chamber.

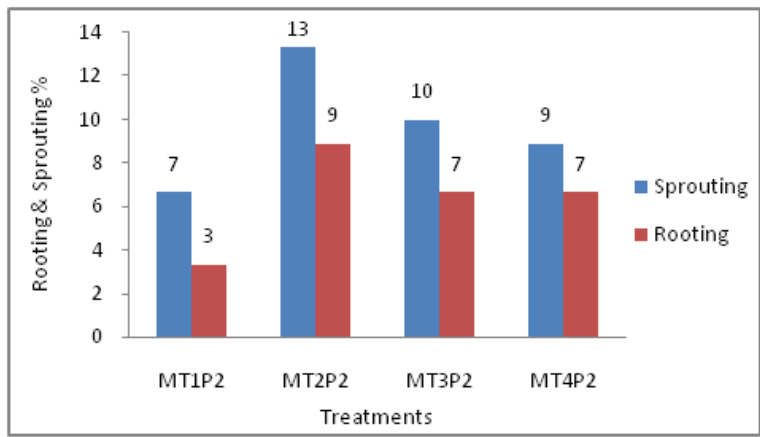

Fig. 2. Effect of IBA concentration on sprouting \& rooting percentage in Shade house.

TABLE 2: GERMINATION PERCENTAGE IN DIFFERENT PRESOWING WATER TREATMENTS, MEDIUMS \& PLACES.

\begin{tabular}{|c|c|c|c|}
\hline \multirow[b]{2}{*}{ Medium } & \multicolumn{3}{|c|}{ Germination \% } \\
\hline & $\begin{array}{l}\text { Mist chamber } \\
\text { (P1) }\end{array}$ & $\begin{array}{c}\text { Shade house } \\
\text { (P2) }\end{array}$ & $\begin{array}{c}\text { Open beds } \\
\text { (P3) }\end{array}$ \\
\hline \multicolumn{4}{|c|}{ Treatment (T1) - Normal water soaking for 12 hours } \\
\hline Sand (M1) & 87 & 73 & 23 \\
\hline Sand+Soil (M2) & 77 & 61 & 65 \\
\hline Soil (M3) & 88 & 58 & 63 \\
\hline \multicolumn{4}{|c|}{ Treatment (T2) Warm water soaking for 12 hours } \\
\hline Sand (M1) & 82 & 80 & 30 \\
\hline Sand +Soil (M2) & 92 & 68 & 60 \\
\hline Soil (M3) & 95 & 53 & 15 \\
\hline \multicolumn{4}{|c|}{ (C) Control } \\
\hline Sand (M1) & 90 & 45 & 11 \\
\hline Sand +Soil (M2) & 68 & 49 & 47 \\
\hline Soil (M3) & 85 & 70 & 57 \\
\hline
\end{tabular}

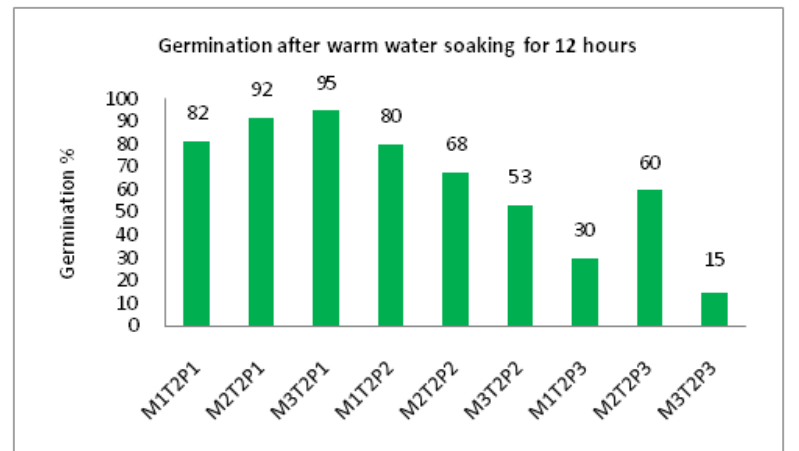

Fig. 3. Effect of normal water soaking for 12 hours on seed germination in different mediums \& different places.

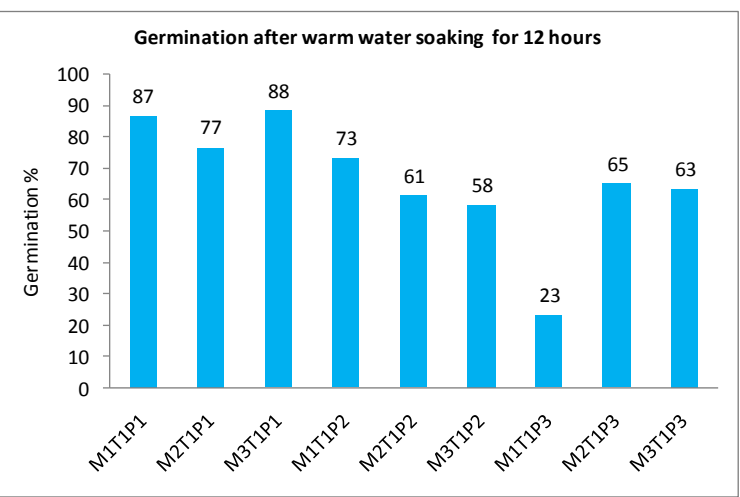

Fig.4. Effect of Hot water soaking for 12 hours on seed germination in different mediums \& different places.

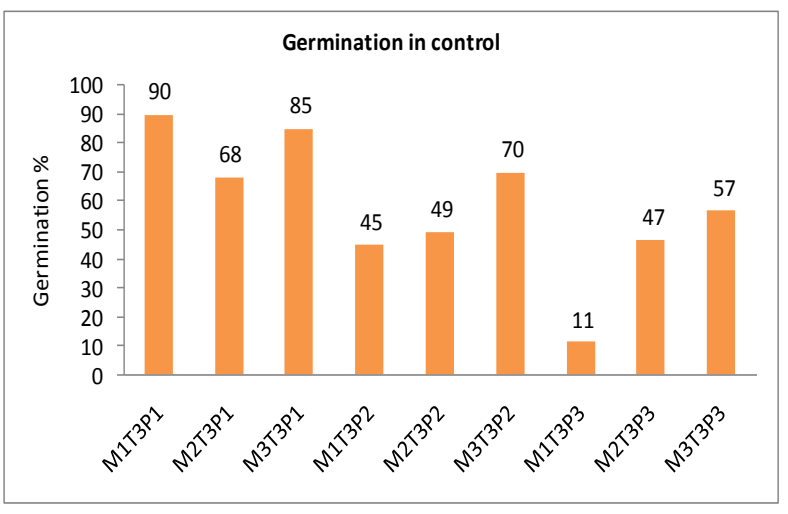

Fig.5. Control seed germination in different mediums \& different places.

\section{IV.RESULT AND DISCUSSION}

Development of nursery technique is a very important tool to raise desired genetic plants in a short period and fulfilling the aim of enhancing the desired population and species conservation. Previous studies showed that it can be propagated easily by seed after giving pre sowing cold stratification. Seed germinated best if given 2 months cold stratification. Germination may be inhibited by light. Seed should be immersed in water for 24-36 hours to soften the hard seed coat. (N.S. Chauhan, 1999) The knowledge of exact stage of seed collection is of immense importance to avoid the collection of immature and non-viable seeds. (R.L.Willian 1985) Cuttings of half-ripe wood, July/August in a frame (M. A. Dirr. and M. W. Heuser, 1987). The treatment of different IBA ppm concentration and Rootex were studied to understand their effect in promoting sprouting and rooting percentage in Prinsepia utilis under Mist chamber and Shade house in sand beds. The data in Table 1 indicated that cutting pretreated with Rootex-3 produced maximum $38 \%$ rooting and $51 \%$ sprouting in mist chamber followed by $23 \%$ rooting and $23 \%$ sprouting in IBA 5000 PPM under mist chamber (Figure 1). Shade house reduced rooting and sprouting percentage as $9 \%$ and $13 \%$ respectively. Among the places cutting performed higher rooting and sprouting percentage in mist chamber compare to shade house while on the other hand treatment Rootex-3 observed higher rooting and sprouting percentage compare to IBA treatments. 
Pre sowing water treatments, mediums and places were studied to analyze the seed germination. The data in Table 2 indicate that maximum $95 \%$ germination observed in Mist chamber (P1) with Sand + Soil (M2) after normal water soaking for 12 hours (T1) followed by $58 \%$ in shade house with sand (M1) after normal water soaking for 12 hours. (T1) (Fig 4) Hot water soaking 12 hours decreased germination percentage $14 \%$ in sand + soil under mist chamber. (Fig. 5) untreated seeds (control) were observed $40 \%$ germination in Mist chamber (P1) with sand + soil (T2) (Fig. 6). Higher germination found after normal water soaking for 12 hours (T1) compare to others pre-sowing water treatment. Among the places mist chamber observed maximum germination percentage compare to other places. Among the mediums mixture of sand + soil was found maximum germination percentage compare to other mediums. The overall results of this study indicate that seed sowing after ripening of seeds is significant more suitable and easy method for artificial reproduction. On the other hand cutting propagation is more time taking and gives lesser result compare to seed germination. So we recommend artificial regeneration by seed sowing for utmost result within a short time.

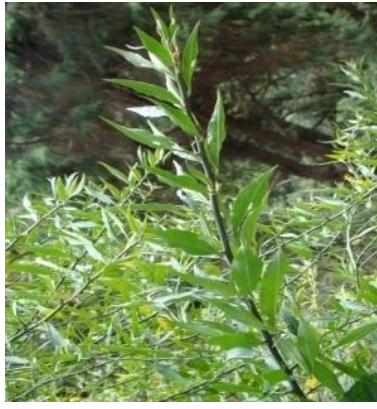

(A )

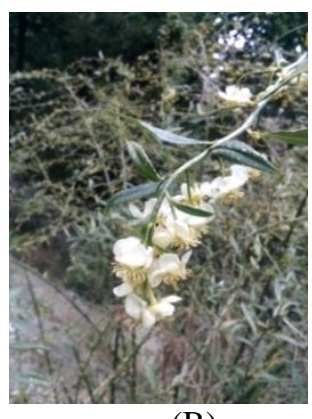

(B)

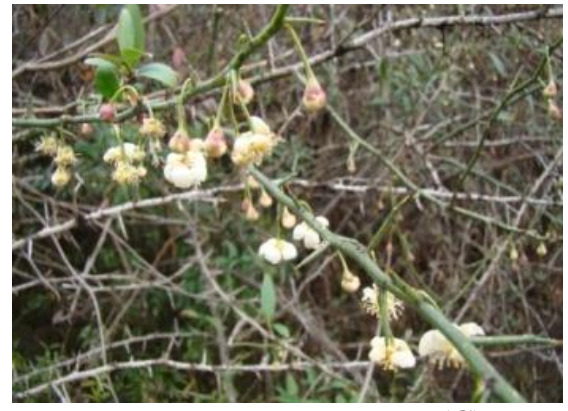

(C)

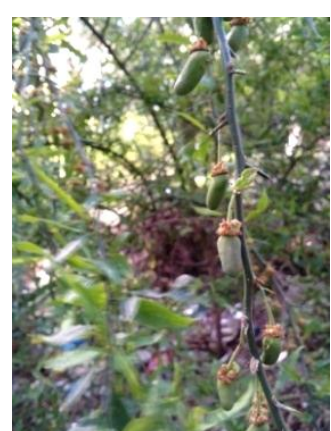

(D)

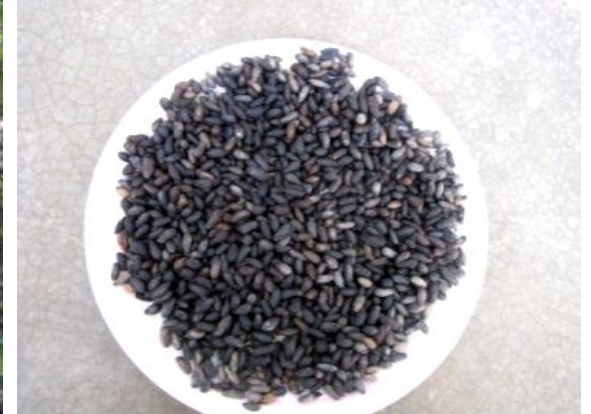

(E)

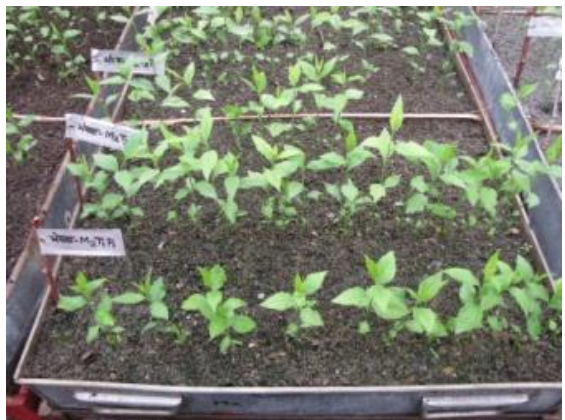

(F)

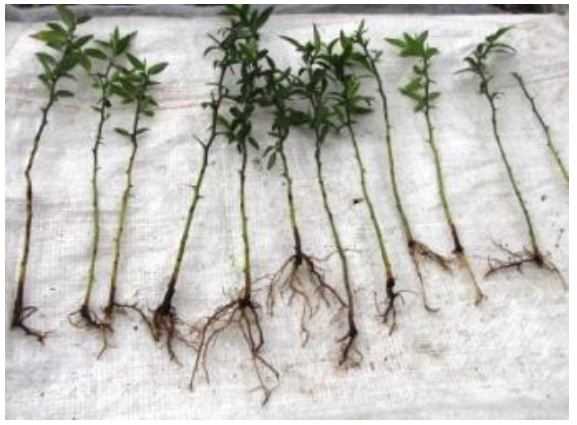

(G)

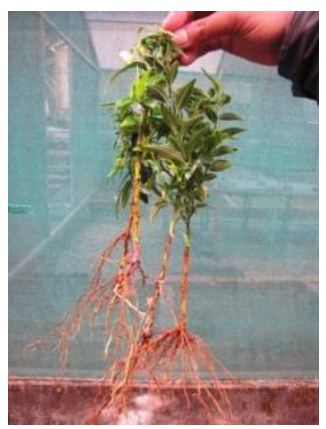

(H)

Photoplate.1: (A) A view of Prinsepia utilis (B -C) Flowering (D) Fruiting (E) Cleaned seeds (F) Seed germination in tray $(\mathrm{G}-\mathrm{H})$ Rooted cuttings

\section{REFERENCES}

[1] Chauhan, N.S 1999, Medicinal and Aromatic plants of Himachal Pradesh, Indus publishing company FS-5, Tagore Garden, New Delhi.

[2] Huxley. A, 1992, The New RHS Dictionary of Gardening

[3] G. Kunkel, 1984, Plants for Human Consumption. An excellent book with a brief list of edible parts.

[4] N. P. Manandhar, 2002, Plants and People of Nepal Excellent book, covering over 1,500 species of useful plants from Nepal together with information on the geography and peoples of Nepal. Good descriptions of the plants with terse notes on their uses.

[5] Dirr. M. A. and M. W. Heuser. The Reference Manual of Woody Plant, 1987.
[6] Willian R.L. (1985). A guide to forest seed handling with special reference to the tropics. FAO Forestry Paper, 20/2. FAO, Rome, $379 \mathrm{pp}$

\section{BIOGRAPHIES}

Vivek Pandey (I.F.S), Conservator of Forest, Forest Research Circle, Haldwani, Uttarakhand, India.

Parvez Daudi Junior Scientific Assistant, Research wing of Uttarakhand, Forest Department, Nainital, India 